\title{
Electrochemical quantification of copper based alloys using voltammetry of microparticles: Optimization of the experimental conditions
}

\author{
Farzin Arjmand and Annemie Adriaens \\ Department of Analytical Chemistry, Ghent University, Krijgslaan 281-S12, 9000 Ghent, Belgium \\ *Corresponding author: annemie.adriaens@ugent.be
}

Key words Voltammetry of microparticles. Carbon paste electrode. Central composite design. Brass. Lead bronze. Copper

\begin{abstract}
Voltammetry of microparticles (VMP) has been used in this work for the qualitative and quantitative analysis of zinc, tin, lead and copper in binary, ternary or quaternary alloy samples. The analyses were carried out by spiking small amounts of the metals into a carbon paste electrode, after which they were anodically stripped off using differential pulse voltammetry. The work involved four separate experiments. The first one examined the type of electrolyte, which is suitable to identify the four elements. More specifically the aim was to examine in which electrolyte all elements can be measured simultaneously - as would be the case in a quaternary copper alloy - without seeing any overlap in their current peaks. The second experiment focused on optimizing the measurement conditions with the aim of having the current peaks of each element well separated from the others. For this part we made use of the central composite design. The aims were to: (i) maximize the separation between current peaks; (ii) to determine which variable has a higher impact on the response; (iii) give an insight in the robustness of the method close to the optimum conditions and (iv) eventually show interactions between variables. In the third experiment the four elements were quantified in their binary mixtures. Here, the percentage of the oxidation current for each metal, which is directly related to the ratio of the metal in the binary matrices, was employed for the calibration. Finally in the last experiment the elements were quantified in two real quaternary samples: a brass and a lead bronze.
\end{abstract}

\section{Introduction}

Abrasive stripping voltammetry (AbSV), also known as voltammetry of immobilized microparticles (VMP) is a simple, fast and cheap electrochemical technique that has been described by F. Scholz in the late 1980's [1, 2]. It is a complementary and very versatile tool used for solid-state characterization [3, 4]. In brief, small amounts of the solid sample are transferred onto the surface of a Paraffin Impregnated Graphite Electrode (PIGE) or onto a Carbon Paste Electrode (CPE). Using voltammetric techniques such as cyclic voltammetry, square wave or differential pulse voltammetry the electrochemical behaviour of the solid sample is then studied.

Since the description of VMP by F. Scholz, the method has been used for the identification of a large variety of samples and to a considerable extent also for their quantification. Regarding the latter, several attempts using different methods have been reported. In $1990 \mathrm{Scholz}$ for the first time described a method for the quantitative determination of tin and bismuth using the ratio of the tin and bismuth peak currents [5]. The same method was 
also used to quantify powder mixtures such as $\mathrm{HgO}, \mathrm{HgS}$ and $\mathrm{PbO}$ [6]. Later on Scholz reported on the use of charge values of different compounds as a means of VMP quantification [7]. This technique was also used by Domenech et al. for the quantitative analysis of the $\mathrm{Fe}(\mathrm{III}) / \mathrm{Fe}(\mathrm{II})$ ratio and some other metal ions [8,9]. Cepria et al. made use of an internal standard for the quantification of cadmium pigments [10]. In 2006 Domenech used the standard addition method for the quantification of lead and tin in archaeological glazes [11]. He also reported on the use of Tafel plots for quantifying cobalt and copper pigments [12].

In the present work, VMP has been applied to a carbon paste electrode (CPE) to identify and quantify metals such as zinc, tin, lead and copper. Quantification is done by using the percentage of the current for each metal. This procedure overcomes the problem that the actual current does not indicate the real amount of the solid sample as the peak current depends on the amount of substance which participates in an electrochemical reaction during the measurement. In VMP analyses only part of the sample undergoes an electrochemical reaction and the analyst cannot control the process [9].

In order to have accurate results, it is also important that the voltammetric peaks are well separated from each other. Therefore, prior to the quantification study, different electrolytes were studied and an optimization technique called central composite design was used in this study. Finally using the optimum conditions, the identification and quantification of the metals in their binary, ternary or even quaternary mixtures/ alloys were performed.

\section{Experimental}

Reagents, equipment and measurements

Solid paraffin, copper, acetic acid, sodium acetate, sodium nitrate, sodium chloride, sodium sulfate, oxalic acid, potassium sulfate and ammonium dichromate were purchased from Merck. Potassium dichromate, ammonium carbonate, ammonium chloride, ammonium acetate, ammonium per sulfate, tri-ammonium orthophosphate, tin, zinc and lead powders were purchased from Aldrich. Graphite $(\leq 0.1 \mathrm{~mm})$ was obtained from Fluka. All reagents were of analytical grade. Brass and lead-bronze alloys containing copper, tin, lead and zinc were available from a previously performed RTD European project within FP5, which had the goal to produce and certify a set of copper alloys having a composition representative for typical archaeological copper alloys in Western Europe [13].

The VMP measurements were performed using an Autolab Eco Chemie potentiostat (PGSTAT 10) in a threeelectrode cell with a $\mathrm{Ag} / \mathrm{AgCl} / \mathrm{KCl}$ (sat) reference electrode and a graphite wire as auxiliary electrode. The working electrode was a carbon paste electrode, $5 \mathrm{~mm}$ in diameter and $85 \mathrm{~mm}$ in length. All measurements were performed using differential pulse voltammetry in a potential window between $-1.50 \mathrm{~V}$ and $0.5 \mathrm{~V}$.

\section{Procedure for the fabrication of the carbon paste electrodes}

All carbon paste electrodes were fabricated using the same conditions. The carbon paste was prepared by carefully mixing $60 \%$ graphite $(\leq 0.1 \mathrm{~mm})$ with $40 \%$ paraffin [14]. A total of $100 \mathrm{mg}$ of the mixed solid paste was transferred to a crucible and $40 \mathrm{mg}$ of the solid analyte to be analyzed was added into the crucible. The 
crucible was placed inside an oven for a few minutes at a temperature of $100{ }^{\circ} \mathrm{C}$, after which the liquid paste was mixed again to obtain a homogeneous paste. After 5 minutes at room temperature the paste was solid again and ready to be used. The solid paste containing the analyte was packed into a plastic tubing body with a length of 20 $\mathrm{mm}$ and a width of $5 \mathrm{~mm}$ diameter and a copper rod with a length of $75 \mathrm{~mm}$ was inserted to pack the paste and to push it to renew the surface and to achieve the electrical contact. The electrode was polished on a sheet of white paper after each measurement to flatten and clean its surface. The exposed surface of the electrode was circular and $5 \mathrm{~mm}$ in diameter. Figure 1 shows a schematic of a carbon paste electrode.

\section{Experimental Design}

A central composite design (CCD) was implemented in order to optimize the resolution between the current peaks observed in the differential pulse voltammetry experiments of the different elements.

The aims were to: (i) maximize the separation between current peaks; (ii) to determine which variable has a higher impact on the response; (iii) give an insight in the robustness of the method close to the optimum conditions and (iv) eventually show interactions between variables.

The variables considered in the optimization process were the scan rate $(0.5-10 \mathrm{mV} / \mathrm{s})$ and the concentration of the electrolyte $(0.01-2 \mathrm{M})$. The polynomial equations, response surface and central design for a particular response were obtained using the statistical software package Essential Regression 97 [15]. For an experimental design with two factors, the model includes linear, quadratic, and cross terms and can be expressed by Eq-1:

$$
\text { Response }=b 0+b 1 \times \mathrm{F} 1+b 2 \times \mathrm{F} 2+b 3 \times \mathrm{F} 1 \times \mathrm{F} 1+b 4 \times \mathrm{F} 2 \times \mathrm{F} 2+b 5 \times \mathrm{F} 1 \times \mathrm{F} 2 \quad(\mathrm{Eq}-1)
$$

Where $F_{1}$ and $/ F_{2}$ are the variable parameters, and $b_{0}$ through $b_{5}$ are the coefficient values obtained through a multivariate linear regression. $b 0$ indicates the intercept and an in error calculation has been used. The statistical significance of the predicted model was evaluated by an analysis of variance (ANOVA) and least square techniques. Replicates $(n=4)$ of the central points were performed to estimate the experimental error.

\section{Results and Discussion}

In what follows the results of four different experiments are given. The first experiment examines the type of electrolyte, which is suitable to identify the elements $\mathrm{Cu}, \mathrm{Sn}, \mathrm{Pb}$ and $\mathrm{Zn}$. More specifically the aim is to examine in which electrolyte all 4 elements can be measured simultaneously - as would be the case in a quaternary copper alloy - without seeing any overlap in their current peaks. The second experiment focuses on optimizing the measurement conditions with the aim of having the current peaks of each element well separated from the others. For this part we make use of the central composite design. In the third experiment the four elements are being quantified in their binary mixtures. Finally in the last experiment the elements are quantified in two real quaternary samples: a brass and a lead bronze.

A cyclic voltammogram of the bare carbon paste electrode in a $1 \mathrm{M}$ oxalic acid solution is shown in Figure 2. It is clear that the carbon paste electrode covers a wide potential range and in comparison to some other working 
electrodes such as hanging or dropping mercury electrode it shows a very small anodic and cathodic residual current.

In a next step copper, tin, lead and zinc were studied individually and as a mixture of all of them in 15 different electrolytes. The electrolytes are listed in Table 1 together with the obtained results. The table demonstrates that the only common electrolyte in which all four metals can be determined is ammonium chloride. For all other electrolytes at least two of the elements overlap with their signals. Although, the exact electrochemical reactions which occur on the surface of a carbon paste electrode are not known and also particular alloy phases may cause the occurrence of some of the peaks, it is clear that each metal has a major current peak which allows us to detect each of them individually (Figure 3). In what follows these signals will be treated using chemometrics.

To obtain the maximum separation between the current peaks and to overcome any interference between them, the concentration of the electrolyte and the scan rate were optimized using the central composite design. Table 2 shows the levels of the coded and actual experimental variables that were tested and the corresponding response of each experiment (i.e. the $|\Delta E|$ values for each of the three couples $\mathrm{Zn}-\mathrm{Sn}, \mathrm{Sn}-\mathrm{Pb}$ and $\mathrm{Pb}-\mathrm{Cu}$ ). According to Figure 3, $\left|\Delta E_{1}\right|$ shows the separation between the second oxidation peak of zinc and the first oxidation peak of tin, $\left|\Delta E_{2}\right|$ represents the difference between the peak potentials of the first oxidation peak of tin and the first peak of lead and finally $\left|\Delta E_{3}\right|$ shows the separation between the second peak of lead and the first oxidation peak of copper which here is common with tin. Table 3 lists the p-values, obtained from the ANOVA, for the zinc-tin, tin-lead and lead-copper couples. In statistical analyses p-values are the most commonly used tool to measure evidence against a hypothesis model. The p-value is a probability, with a value ranging from zero to one which shows chance of observing a difference between the real value and the estimated value. For all experiments, the $\mathrm{p}$-value of the second factor (electrolyte concentration) is smaller than p-value of the first factor (scan rate), which means that in these series of experiments the importance of ammonium chloride concentration is higher than the scan rate.

The corresponding 3D surface response plots are shown in Figure 4. For the zinc-tin couple (Figure 4a) the maximum separation between the peaks is observed for very low concentrations of $\mathrm{NH}_{4} \mathrm{Cl}(0.01 \mathrm{M})$. At this concentration the scan rate does not have a lot of influence on the $\Delta \mathrm{E}$ value. For the tin-lead couple (Figure $4 \mathrm{~b}$ ) $\mathrm{a}$ maximum separation of the current peaks can be observed for a scan rate of $5.8 \mathrm{mV} / \mathrm{s}$ and a $\mathrm{NH}_{4} \mathrm{Cl}$ concentration of around $1 \mathrm{M}$. Finally for the lead-copper couple (Figure 4c) the resolution of the differential pulse voltammogram increases with lower concentrations of $\mathrm{NH}_{4} \mathrm{Cl}(0.01 \mathrm{M})$. Simultaneously by increasing the scan rate from 0.5 to $10 \mathrm{mV} / \mathrm{s}$ the separation between lead and copper oxidation peaks increases and then decreases again. Using these surface plots one can choose the scan rate $5.8 \mathrm{mV} / \mathrm{s}$ and $\mathrm{NH}_{4} \mathrm{Cl}$ concentration $0.01 \mathrm{M}$ as optimum conditions for lead and copper peak separation. In brief, by comparison of three obtained plots, low concentration of $\mathrm{NH}_{4} \mathrm{Cl}(0.01 \mathrm{M})$ and the scan rate $5.8 \mathrm{mV} / \mathrm{s}$ were selected as optimal conditions for this mixture of metals. Although in differential pulse voltammetry the user can not change the scan rate directly, it can be done by "step E×1/pulse period" where the pulse period must be at least twice the pulse width.

Figure 5 compares a voltammogram of the four metals taken under optimized conditions (B) and one under a different set of conditions ( $\mathrm{A}:\left[\mathrm{NH}_{4} \mathrm{Cl}\right]: 2 \mathrm{M}$ and scan rate: $\left.10.5 \mathrm{mV} / \mathrm{s}\right)$. In the latter voltammogram the second oxidation peak of zinc completely covers the area of tin and the main oxidation peak of lead overlaps with the sharp peak at potential $-0.4 \mathrm{~V}$. However, using optimal conditions a good separation especially between zinc and tin was obtained. 
In the third experiment we aimed to quantify the amounts of each element present in a particular mixture of metal powders. In this work the quantification of two elements was made by calculating the percentage of current for each metal. For example for a copper-lead mixture the correlation between the oxidation currents of copper $\left(I_{\mathrm{Cu}}\right)$ and lead $\left(I_{\mathrm{Pb}}\right)$ and the percentage of current for these metals in their binary mixtures $(I \%)$ is [6] :

$$
\begin{gathered}
I_{\mathrm{Cu}}(\%)=\frac{I_{\mathrm{Cu}}}{I_{\mathrm{Cu}}+I_{\mathrm{Pb}}} \times 100 \\
I_{\mathrm{Pb}}(\%)=\frac{I_{\mathrm{Pb}}}{I_{\mathrm{Cu}}+I_{\mathrm{Pb}}} \times 100
\end{gathered}
$$

When dealing with multi-compound matrices containing more than two metals, one can still make use of the binary calibration as is shown in Figure 6 for a ternary or quaternary alloy.

In the present work zinc, tin and lead were calibrated one by one versus copper and two calibration plots were obtained for each calibration set. To obtain the calibration plots, carbon paste electrodes of $\mathrm{Cu}-\mathrm{Pb}, \mathrm{Cu}-\mathrm{Zn}$ and $\mathrm{Cu}-\mathrm{Sn}$ mixtures in different percentages were prepared and differential pulse voltammograms of each mixture were recorded in the optimum conditions (scan rate: $5.8 \mathrm{mV} / \mathrm{s}$ and $\left[\mathrm{NH}_{4} \mathrm{Cl}\right]: 0.01 \mathrm{M}$ ). At least five measurements were performed for each mixture and the total average of each current was calculated. All voltammograms were recorded using the same scan rate, therefore, the measured peak currents were calculated using the same base line (here zero current). As an example Table 4 shows the composition of the different carbon paste electrodes used for the copper-lead calibration. According to this table, the oxidation peak current percentage of each metal depends directly on the amount of that metal in its binary matrix. Therefore, by increasing the percentage of a metal in a binary mixture, the percentage of the related peak current of that metal increases with a constant slope. In this table the minimum amounts of lead and copper in their binary calibration plot are $0.4 \mathrm{mg}(1 \%)$ and $2 \mathrm{mg}$ (5\%) and their maximum amounts are $38 \mathrm{mg}(95 \%)$ and $39.6 \mathrm{mg}(99 \%)$ respectively. Parallel to increase the amount of lead from 1 to $95 \%$ the percentage of lead oxidation peak current increases from $1 \%$ to $83.4 \%$ of the total amount of the obtained oxidation currents for lead and copper. The same procedure was followed for calibration of copper-tin and copper-zinc couples. The obtained calibration plots with acceptable regression coefficient $\left(0.98 \leq \mathrm{R}^{2}\right)$ are shown in Figure 7 .

One should keep in mind that when a linear calibration curve is used to determine sample concentrations, unrealistically large uncertainties may be assigned to low concentration samples. The reason for this is that at low concentrations, an increasing variety of effects becomes important including, for example, the presence of noise or an unstable baseline. Because of such effects, as the analyte concentrations drop, the relative uncertainty associated with the result tends to increase [16]. In the case of our measurements, as the amounts of lead or copper decrease (Table 4), the expected uncertainty increases which may cause a larger standard deviation for a single measurement. However, replicate measurements in presence of a constant deviation can finally result in smaller standard deviations.

In a next step, the prediction ability of the calibration plots was tested. Two samples from each couple of the metals $(\mathrm{Cu}-\mathrm{Zn}, \mathrm{Cu}-\mathrm{Sn}$ and $\mathrm{Cu}-\mathrm{Pb})$ with different percentages of copper were prepared from the reference metals and the real amounts of each metal in the binary mixtures were predicted. The average and standard deviation were calculated. The results are shown in Table 5. According to Scholz the acceptable range of relative standard deviation for VMP technique is from 3 to $15 \%$ [6]. In this work the relative standard deviations were 
reported between 3.37 for copper till 14.71 for lead. These results confirm that although VMP technique has been used as a typical method for identification of solid compounds, it can also give suitable results in quantification.

Finally VMP under optimized conditions was applied for the analysis of brass and lead-bronze samples. A total of $40 \mathrm{mg}$ of powder was obtained from each alloy using a glass brush. The carbon paste electrodes of the alloys were made using the procedure described above and differential pulse voltammograms of the samples were recorded under the optimum conditions $\left(\mathrm{scan}\right.$ rate $\left.=5.8 \mathrm{mV} / \mathrm{s},\left[\mathrm{NH}_{4} \mathrm{Cl}\right]=0.01 \mathrm{M}\right)$. Although the obtained calibration plots are for binary metals, for the analysis of a quaternary alloy such as brass and lead-bronze one can write:

$$
\begin{aligned}
& {[\mathrm{Cu}]=a \times[\mathrm{Pb}]=b \times[\mathrm{Sn}]=c \times[\mathrm{Zn}]} \\
& {[\mathrm{Cu}]+[\mathrm{Pb}]+[\mathrm{Sn}]+[\mathrm{Zn}]=d(\mathrm{mg} / \mu \mathrm{g})}
\end{aligned}
$$

The first equation shows the estimated values of lead, tin and zinc versus copper using the binary calibration plots and in the second equation $d$ represents the total amount of the alloy sample. Using the binary calibration plots, obtained above, the amounts of zinc, tin, lead and copper in brass and the lead-bronze alloys were determined. Table 6 shows the results together with the certified values [13]. Except for the amount of zinc in the brass, there is no significant difference between the obtained results and the certified values. The errors are sometimes large (up to $15 \%$ ), but we are of the opinion that the procedure of loading the working electrodes can be optimized, which may results in more accurate and precise results.

\section{Conclusions}

Voltammetry of microparticles using a carbon paste electrode is a cheap, simple and also non-destructive method for the identification and even quantification of different alloys. The effect of different electrolytes and other variables such as scan rate and electrolyte concentration were studied using an experimental design method. This allowed us to optimize the measurement conditions leading to voltammograms with clearly resolved peaks. The second part of the paper dealt with the quantification of the metals in powder mixtures, but also in real quaternary copper alloys and gave satisfactory results.

\section{Acknowledgements}

The authors acknowledge BOF at Ghent University for funding this work.

\section{References}

1. Scholz F, Nitschke, Henrion G (1989) Naturwiss 76:71-72

2. Scholz F, Nitschke, Henrion G, Damschun F (1989) Naturwiss 76:167-168

3. Brainina Kh, Neyman E (1993) Electroanalytical stripping methods. John Wiley and Sons, New York 
4. Scholz F, Meyer B (1993) In: Bard AJ, Rubinstein I (eds) Electroanalytical Chemistry, A Series of Advances (Vol. 20) Marcel Dekker, New York, p 1

5. Scholz F, Nitschke, Henrion G (1990) Electroanalysis 2:85-87

6. Scholz F, Lange B, Jaworski A, Pelzer J (1991) Fresenius J Anal Chem 340:140-144

7. Meyer B, Zhang S, Scholz F (1996) Fresenius J Anal Chem 356:267-270

8. Domenech A, Domenech MT, Cortina L, Adelantado JV (2001) Electroanalysis, 14:685-696

9. Domenech A, Domenech MT, Cortina L, Adelantado JV (2002) Electroanalysis, 15:1465-1475

10. Cepria G, Gareta E, Arantegui J (2004) Electroanalysis, 17:1078-1084

11. Domenech A, Domenech MT, Adelantado JV, Reig F (2006) Anal Bioanal Chem 385:1552-1561

12. Domenech A, Domenech MT, Edwards HGM (2008) Anal Chem 80:2704-2716

13. Ingelbrecht C, Adriaens A, Maier EA (2001): Certification of arsenic, lead, tin and zinc (mass fractions) in five copper alloys CRM 691. EUR 19778/1, Office for Official Publications of the European Communities, Luxembourg

14. Cepria G, Cepria JJ, Ramajo J (2004) Microchim Acta, 144:139-145

15. http://www.jowerner.homepage.t-online.de/download.htm

16. http://www.measurementuncertainty.org/guide/app_f.html

\section{Figure captions}

Figure 1. Schematic drawing of a carbon paste electrode.

Figure 2. Cyclic voltammogram of a bare carbon paste electrode in oxalic acid $0.1 \mathrm{M}$ solution, scan rate: 50 $\mathrm{mV} / \mathrm{s}$.

Figure 3. Voltamogram showing different oxidation signals of zinc, tin, lead and copper in a $\mathrm{NH}_{4} \mathrm{Cl}$ solution. Different signals of one element are indexed as (A) and (B).

Figure 4. Response surfaces estimated from the central composite design by plotting scan rate vs. $\mathrm{NH}_{4} \mathrm{Cl}$ concentration for the zinc and tin current peaks (a), tin and lead peaks (b) and lead and copper peaks (c).

Figure 5. Differential pulse voltammograms of carbon paste with a zinc, tin, lead and copper mixture electrode (A) $\mathrm{NH}_{4} \mathrm{Cl} 2 \mathrm{M}$, scan rate: $10.5 \mathrm{mV} / \mathrm{s}$. (B) $\mathrm{NH}_{4} \mathrm{Cl} 0.01 \mathrm{M}$, scan rate: $5.8 \mathrm{mV} / \mathrm{s}$ (optimum conditions for quaternary mixture) .

Figure 6. Calibration strategy for ternary and quaternary alloys.

Figure 7. Dependence of the composition of lead-copper (A), zinc-copper (B) and tin-copper (C) mixtures on the peak current of each metal. 


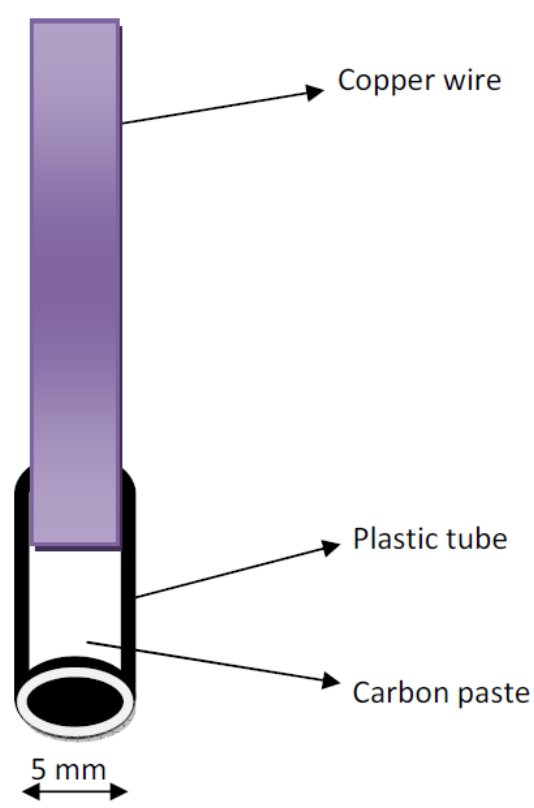

Fig. 1

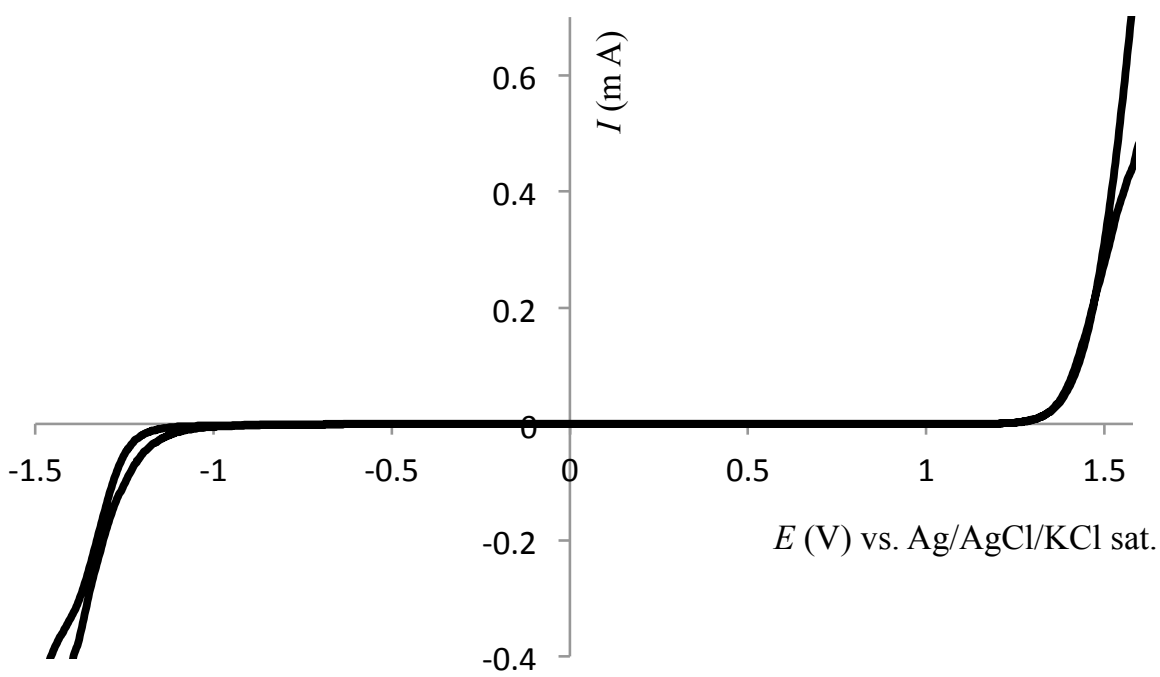

Fig. 2 


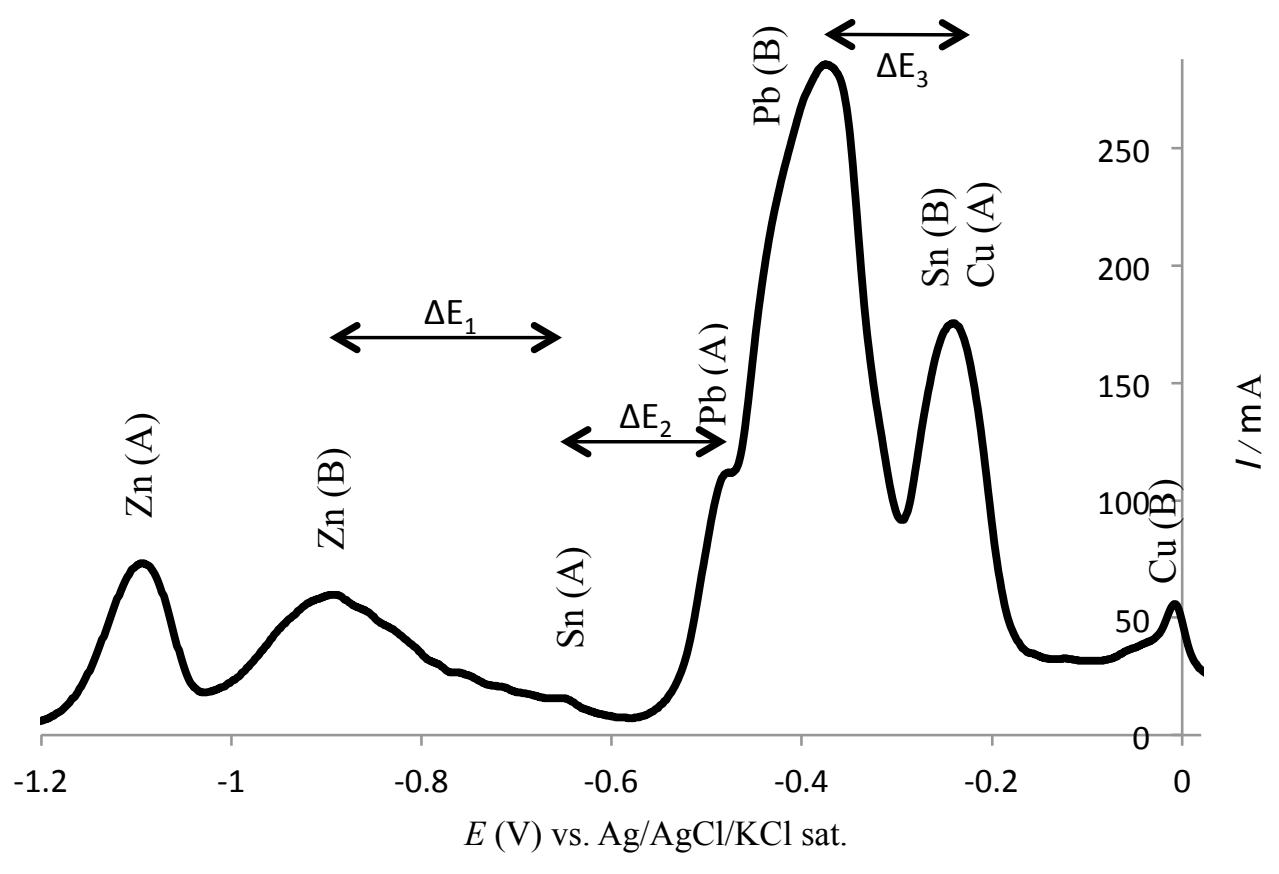

Fig. 3

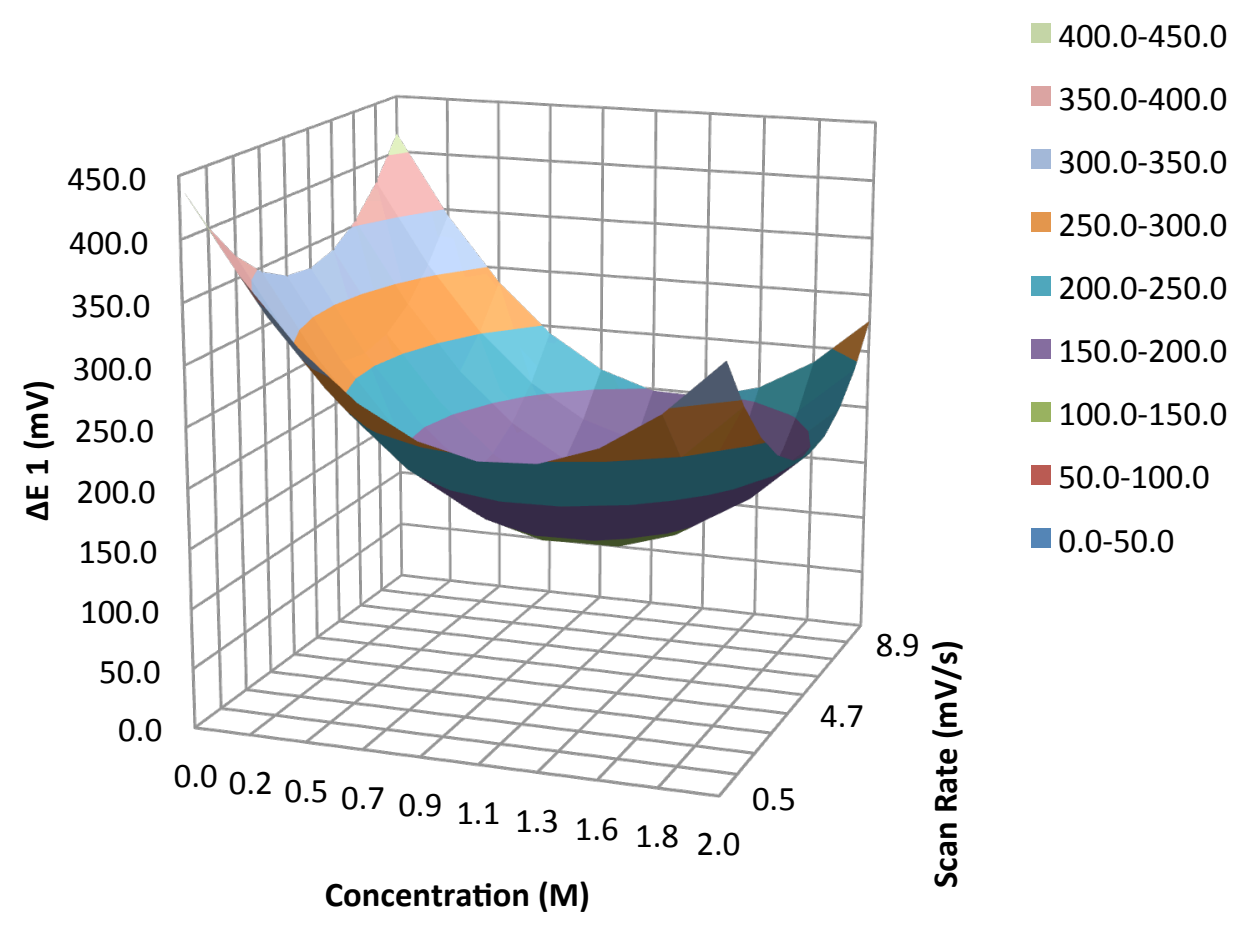

(a) 


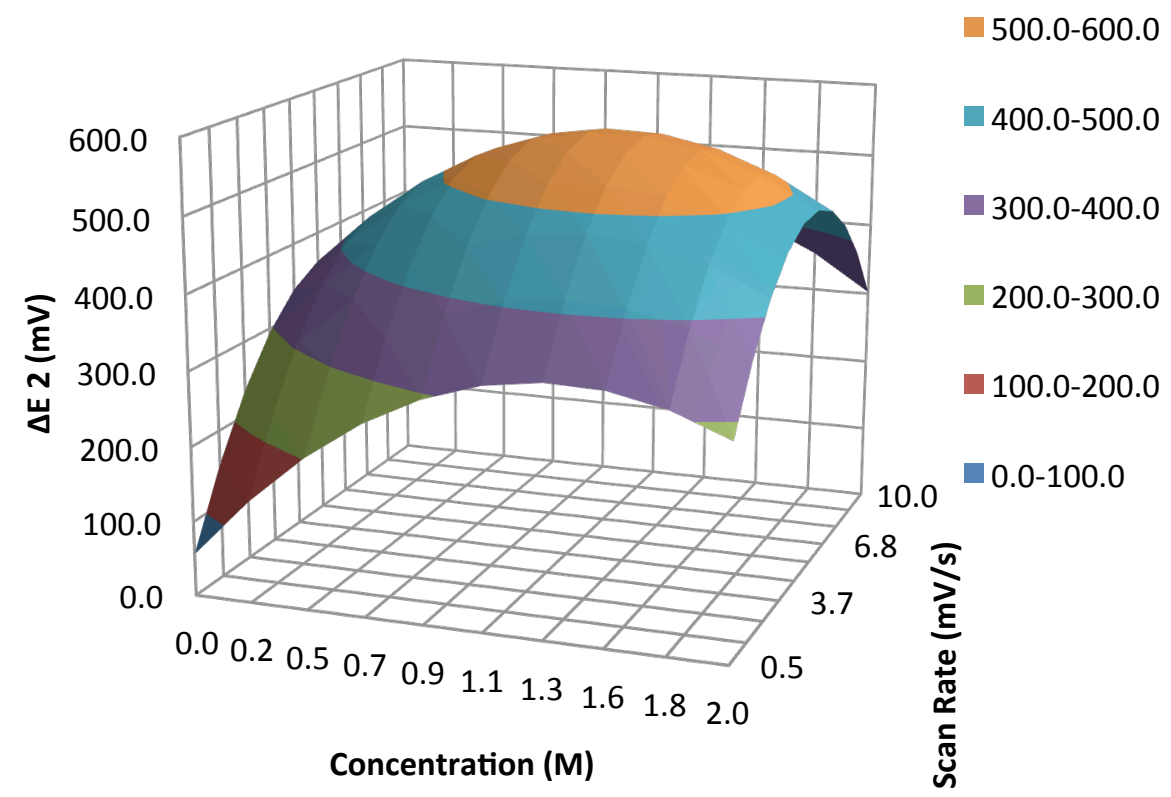

(b)

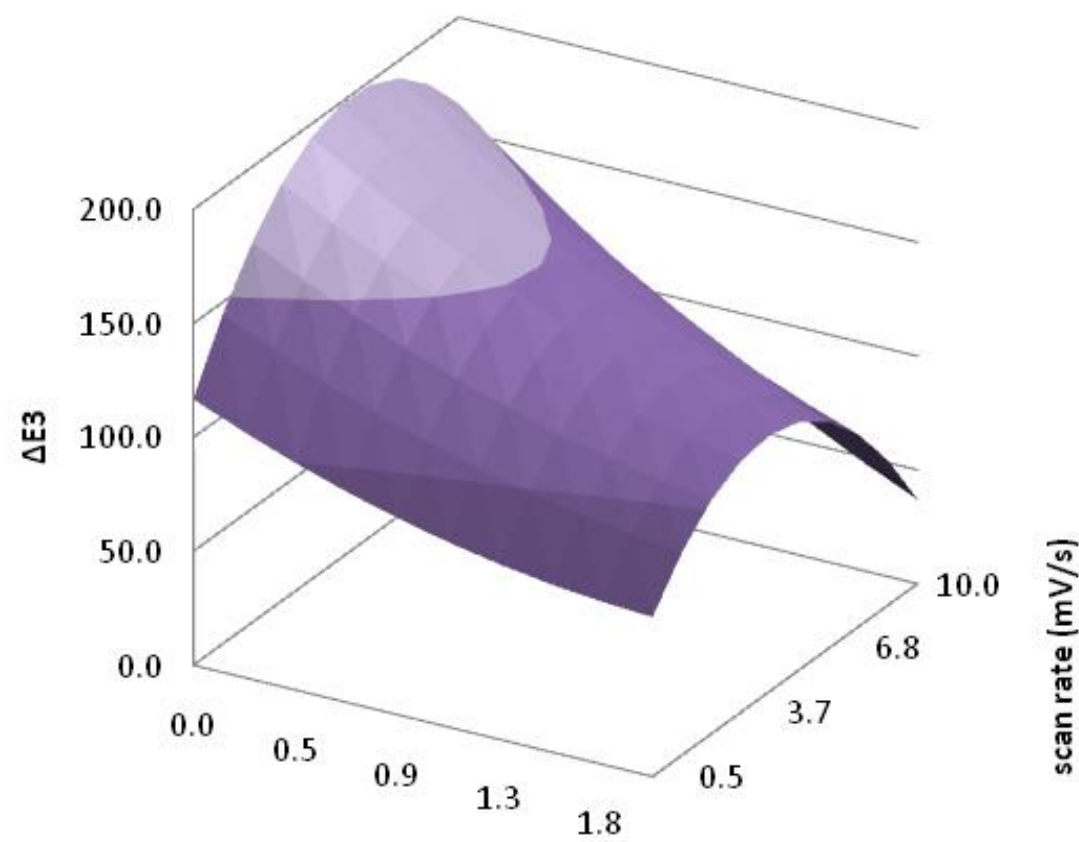

concentration (M)

(c)

Fig. 4 


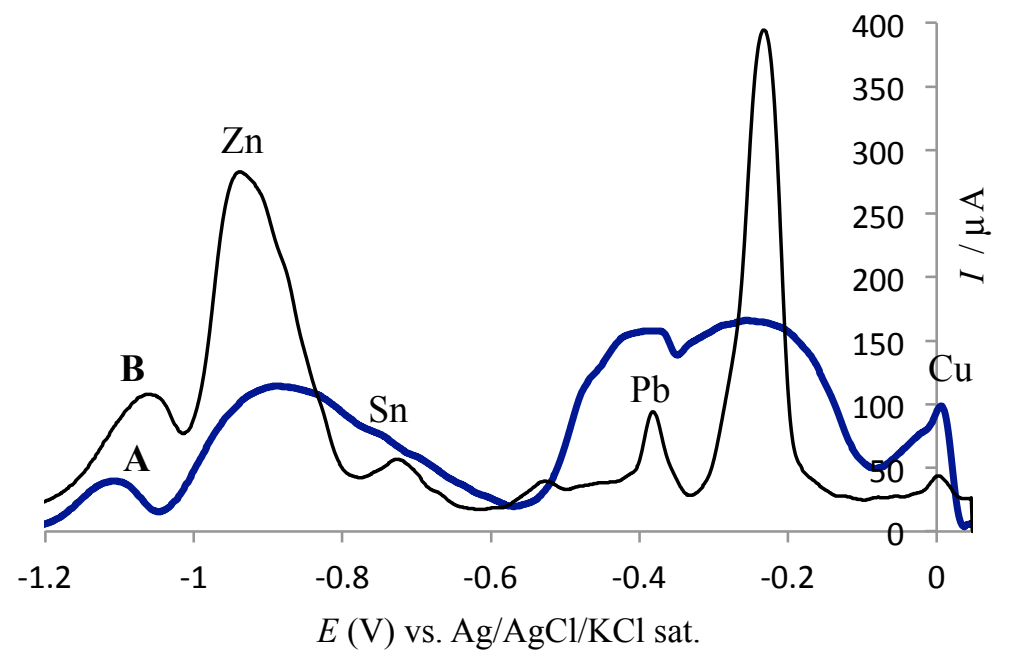

Fig. 5

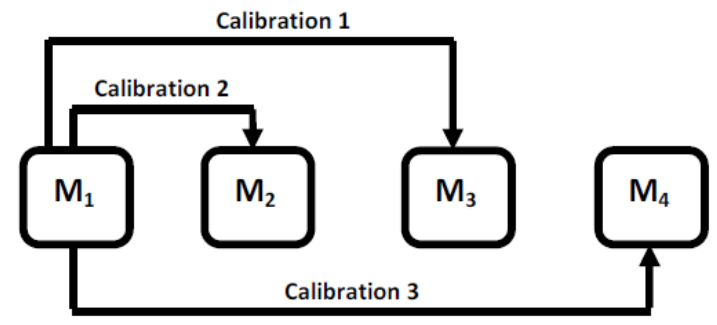

Fig. 6 

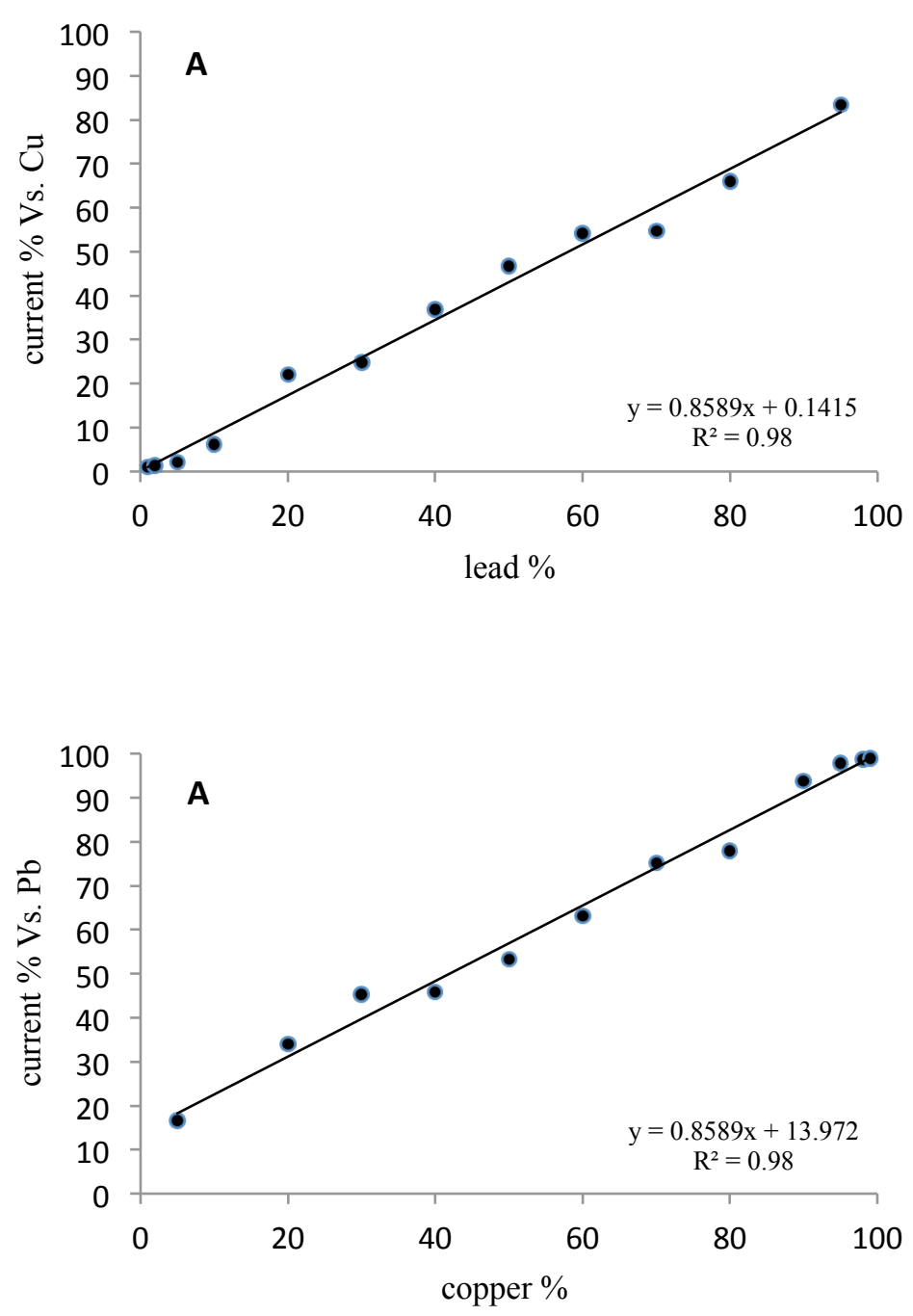

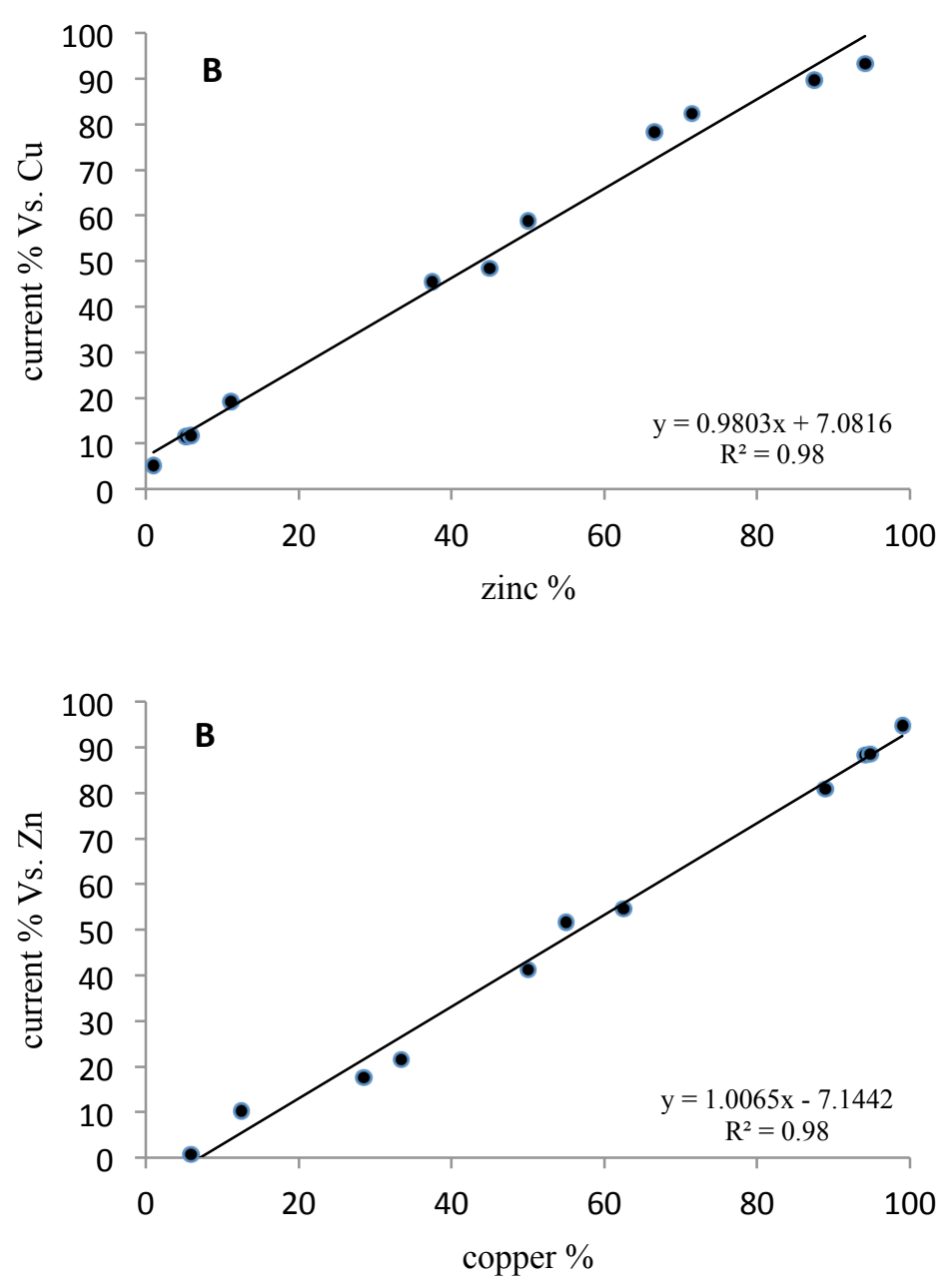

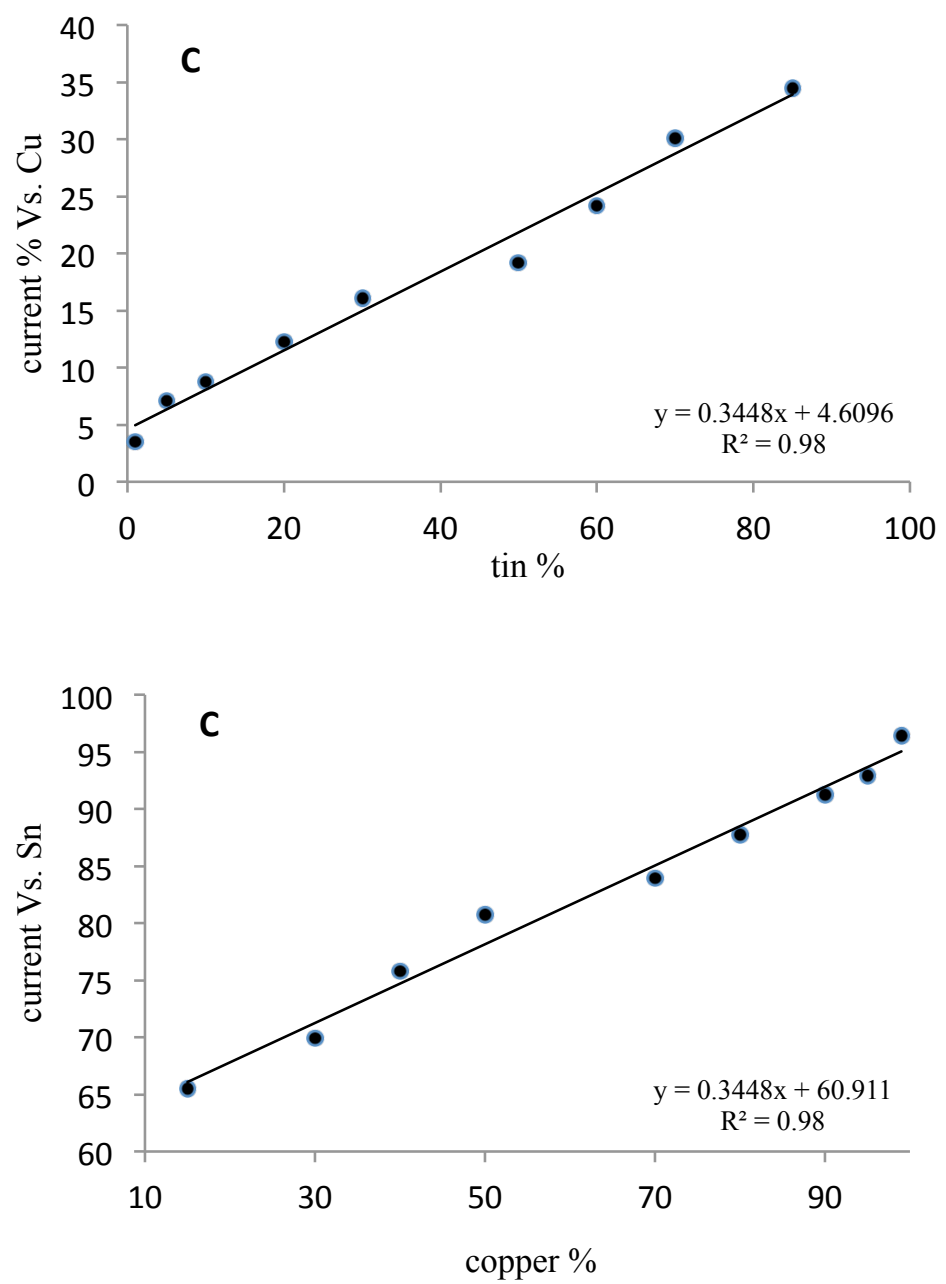

Fig. 7 
Table 1 Different electrolytes used to identify $\mathrm{Zn}, \mathrm{Sn}, \mathrm{Pb}$ and $\mathrm{Cu}$ in their quaternary mixtures ( $\sqrt{ }$ means identifiable, $x$ means not identifiable)

\begin{tabular}{|c|c|c|c|c|c|}
\hline Electrolyte $(0.1 \mathrm{M})$ & $\mathrm{Zn}$ & $\mathrm{Sn}$ & $\mathrm{Pb}$ & $\mathrm{Cu}$ & Overlapping peaks \\
\hline Sodium hydroxide & $\sqrt{ }$ & $\sqrt{ }$ & $x$ & $x$ & $\mathrm{~Pb}-\mathrm{Cu}$ \\
\hline Oxalic acid & $\sqrt{ }$ & $x$ & $x$ & $\sqrt{ }$ & $\mathrm{Sn}-\mathrm{Pb}$ \\
\hline Sodium nitrate & $\sqrt{ }$ & $x$ & $x$ & $\sqrt{ }$ & $\mathrm{Sn}-\mathrm{Pb}$ \\
\hline Acetic acid & $\sqrt{ }$ & $x$ & $x$ & $\sqrt{ }$ & $\mathrm{Sn}-\mathrm{Pb}$ \\
\hline Sodium acetate & $\sqrt{ }$ & $\sqrt{ }$ & $x$ & $x$ & $\mathrm{~Pb}-\mathrm{Cu}$ \\
\hline Sodium sulfate & $\sqrt{ }$ & $x$ & $\sqrt{ }$ & $x$ & $\mathrm{Sn}-\mathrm{Cu}$ \\
\hline Sodium chloride & $\sqrt{ }$ & $x$ & $x$ & $x$ & $\mathrm{Sn}-\mathrm{Pb}-\mathrm{Cu}$ \\
\hline Potassium sulfate & $\sqrt{ }$ & $x$ & $\sqrt{ }$ & $x$ & $\mathrm{Sn}-\mathrm{Cu}$ \\
\hline Potassium dichromate & $\sqrt{ }$ & $x$ & $x$ & $x$ & $\mathrm{Sn}-\mathrm{Pb}-\mathrm{Cu}$ \\
\hline Ammonium carbonate & $\sqrt{ }$ & $x$ & $x$ & $x$ & $\mathrm{Sn}-\mathrm{Pb}-\mathrm{Cu}$ \\
\hline Ammonium chloride & $\sqrt{ }$ & $\sqrt{ }$ & $\sqrt{ }$ & $\sqrt{ }$ & ------- \\
\hline Ammonium acetate & $\sqrt{ }$ & $x$ & $x$ & $x$ & $\mathrm{Sn}-\mathrm{Pb}-\mathrm{Cu}$ \\
\hline Ammonium persulfate & $x$ & $x$ & $\sqrt{ }$ & $\sqrt{ }$ & $\mathrm{Zn}-\mathrm{Sn}$ \\
\hline Ammonium dichromate & $\sqrt{ }$ & $x$ & $x$ & $x$ & $\mathrm{Sn}-\mathrm{Pb}-\mathrm{Cu}$ \\
\hline $\begin{array}{l}\text { Tri-ammonium } \\
\text { orthophosphate }\end{array}$ & $\sqrt{ }$ & $x$ & $x$ & $x$ & $\mathrm{Sn}-\mathrm{Pb}-\mathrm{Cu}$ \\
\hline
\end{tabular}


Table 2 Design matrix and relative $|\Delta E|$ values in central composite design for two factors: scan rate $(\mathrm{mV} / \mathrm{s})$ and $\mathrm{NH}_{4} \mathrm{Cl}$ concentration $(\mathrm{M})$

\begin{tabular}{|c|c|c|c|c|c|}
\hline Exp. \# & $\begin{array}{c}\mathrm{F}_{1}-\text { Scan Rate } \\
(\mathrm{mV} / \mathrm{s})\end{array}$ & $\begin{array}{c}\mathrm{F}_{2}-\left[\mathrm{NH}_{4} \mathrm{Cl}\right] \\
(\mathrm{M})\end{array}$ & $\begin{array}{c}\left|\Delta E_{1}\right|(\mathrm{mV}) \\
\mathrm{Zn}-\mathrm{Sn}\end{array}$ & $\begin{array}{c}\left|\Delta E_{2}\right|(\mathrm{mV}) \\
\mathrm{Sn}-\mathrm{Pb}\end{array}$ & $\begin{array}{c}\Delta E_{3} \mid(\mathrm{mV}) \\
\mathrm{Pb}-\mathrm{Cu}\end{array}$ \\
\hline $1^{(\mathrm{R})}$ & 0 & 0 & 190.6 & 494.5 & 56.6 \\
\hline $2^{(\mathrm{R})}$ & 0 & 0 & 189.3 & 525.5 & 134.5 \\
\hline $3^{(\mathrm{R})}$ & 0 & 0 & 181.3 & 408 & 150.7 \\
\hline 4 & 0 & 2 & 217.1 & 482.8 & 127.1 \\
\hline 5 & -1 & -1 & 244.9 & 337.5 & 159.2 \\
\hline 6 & -2 & 0 & 404.8 & 104.7 & 80.1 \\
\hline 7 & 1 & -1 & 366.2 & 293.7 & 111.1 \\
\hline 8 & -1 & 1 & 168.4 & 465.7 & 92.9 \\
\hline 9 & 2 & 0 & 237.1 & 451.1 & 163.4 \\
\hline $10^{(\mathrm{R})}$ & 0 & 0 & 206.2 & 468.9 & 82.3 \\
\hline 11 & 1 & 1 & 182 & 454 & 91.8 \\
\hline 12 & 0 & -2 & 436 & 239.3 & 204 \\
\hline Coded value $(-2)$ & 0.5 & 0.01 & - & - & - \\
\hline Coded value (-1) & 1.89 & 0.06 & - & - & - \\
\hline Coded value (0) & 4.25 & 0.5 & - & - & - \\
\hline Coded value $(+1)$ & 8.31 & 1.4 & - & - & - \\
\hline Coded value $(+2)$ & 10 & 2 & - & - & - \\
\hline
\end{tabular}

(R): replicated experiment. $(n=4)$

Table $3 \mathrm{P}$-values for each series of experiments, $\Delta E_{1}(\mathrm{Zn}-\mathrm{Sn}), \Delta E_{2}(\mathrm{Sn}-\mathrm{Pb})$ and $\Delta E_{3}(\mathrm{~Pb}-\mathrm{Cu})$

\begin{tabular}{|cccc|}
\hline coefficient & p-value $\left(\Delta E_{1}\right)$ & p-value $\left(\Delta E_{2}\right)$ & p-value $\left(\Delta E_{3}\right)$ \\
\hline$b 0$ & 0.005 & 0.039 & 0.039 \\
\hline$b 1$ & 0.228 & 0.971 & 0.971 \\
\hline$b 2$ & 0.099 & 0.166 & 0.166 \\
\hline$b 3$ & 0.203 & 0.939 & 0.939 \\
\hline$b 4$ & 0.094 & 0.181 & 0.181 \\
\hline$b 5$ & 0.920 & 0.778 & 0.778 \\
\hline
\end{tabular}


Table 4 Different compositions of the carbon paste electrodes and the percentage of the oxidation current for copper and lead for each electrode (total amount of the sample $40 \mathrm{mg}$ )

\begin{tabular}{|ccccc|}
\hline CPE & $\mathrm{Cu}(\%)$ & $\mathrm{Pb}(\%)$ & $I_{\mathrm{Cu}}(\%)$ & $I_{\mathrm{Pb}}(\%)$ \\
\hline 1 & 5 & 95 & 16.57 & 83.42 \\
\hline 2 & 20 & 80 & 33.90 & 66.09 \\
\hline 3 & 30 & 70 & 45.2 & 54.8 \\
\hline 4 & 40 & 60 & 45.8 & 54.2 \\
\hline 5 & 50 & 50 & 53.36 & 36.8 \\
\hline 6 & 60 & 40 & 63.2 & 24.7 \\
\hline 7 & 70 & 30 & 75.3 & 22.74 \\
\hline 8 & 80 & 20 & 77.92 & 6.15 \\
\hline 9 & 90 & 10 & 93.84 & 2.14 \\
\hline 10 & 95 & 5 & 97.85 & 1.32 \\
\hline 11 & 98 & 2 & 98.67 & 1 \\
\hline 12 & 99 & 1 & 99 & 563 \\
\hline
\end{tabular}

Table 5 The predicted amounts of copper, lead, zinc and tin using $\mathrm{Cu}-\mathrm{Zn}, \mathrm{Cu}-\mathrm{Pb}$ and $\mathrm{Cu}-\mathrm{Sn}$ couples (total amount of each couple: $40 \mathrm{mg}$ ) and standard deviations

\begin{tabular}{|c|c|c|c|c|c|c|}
\hline Metal & $\begin{array}{l}\text { Sample } 1^{*} \\
\text { (mg) }\end{array}$ & $\begin{array}{l}\text { Sample 2* } \\
\text { (mg) }\end{array}$ & $\begin{array}{c}\text { Std } \\
\text { (Sample 1) }\end{array}$ & $\begin{array}{c}\text { Std } \\
\text { (Sample 2) }\end{array}$ & $\begin{array}{c}\text { RSD\% } \\
\text { (Sample 1) }\end{array}$ & $\begin{array}{c}\text { RSD\% } \\
\text { (Sample 2) }\end{array}$ \\
\hline $\mathrm{Cu}(\mathrm{Cu}-\mathrm{Zn})$ & $\begin{array}{l}\text { Added: } 5 \\
\text { Found: } 4.70\end{array}$ & $\begin{array}{l}\text { Added: } 30 \\
\text { Found: } 30.13\end{array}$ & 0.66 & 1.01 & 13.36 & 3.37 \\
\hline $\mathrm{Pb}(\mathrm{Cu}-\mathrm{Pb})$ & $\begin{array}{l}\text { Added: } 10 \\
\text { Found: } 10.84\end{array}$ & $\begin{array}{l}\text { Added: } 34.80 \\
\text { Found: } 34.93\end{array}$ & 1.47 & 2.84 & 14.71 & 8.18 \\
\hline $\mathrm{Zn}(\mathrm{Cu}-\mathrm{Zn})$ & $\begin{array}{l}\text { Added: } 10 \\
\text { Found: } 9.75\end{array}$ & $\begin{array}{l}\text { Added: } 35 \\
\text { Found: } 34\end{array}$ & 1.37 & 2.33 & 13.37 & 6.68 \\
\hline $\mathrm{Sn}(\mathrm{Cu}-\mathrm{Sn})$ & $\begin{array}{l}\text { Added: } 12 \\
\text { Found: } 12.28\end{array}$ & $\begin{array}{l}\text { Added: } 20 \\
\text { Found: } 19.26\end{array}$ & 0.55 & 5.23 & 4.78 & 9.53 \\
\hline
\end{tabular}

*Replicated: 5 times 
Table 6 Certified [13] and determined values $(\mathrm{g} / \mathrm{kg})$ for zinc, tin and lead using VMP and the obtained calibration plots for binary mixtures. Total amount of the alloys used is $40 \mathrm{mg}$. Every analysis was repeated 5 times.

\begin{tabular}{|c|c|c|c|c|}
\hline & \multicolumn{2}{|c|}{ Brass } & Lead bronze \\
& Certified value & Determined value & Certified value & Determined value \\
\hline $\mathrm{Zn}$ & $148 \pm 5$ & $119 \pm 9$ & $1.48 \pm 0.24$ & $1.4 \pm 0.2$ \\
\hline $\mathrm{Sn}$ & $20.6 \pm 0.7$ & $22 \pm 3$ & $101 \pm 8$ & $88 \pm 14$ \\
\hline $\mathrm{Pb}$ & $3.9 \pm 0.3$ & $4.2 \pm 0.6$ & $92 \pm 17$ & $93.1 \pm 3.7$ \\
\hline
\end{tabular}

